\title{
Variation in the colour of the keel petals in Lotus corniculatus L. 3. Pollination, herbivory and seed production
}

\author{
David A. Jones*, \\ S. G. Comptont, \\ T. J. Crawford $\ddagger$, \\ W. M. Ellis $\S$ \\ and I. M. Taylor*
}

\author{
* Department of Plant Biology and Genetics, \\ University of Hull, Hull HU6 7RX, England. \\ $\dagger$ Department of Zoology and Entomology, \\ Rhodes University, Grahamstown 6140, South Africa. \\ ¥Department of Biology, University of York, \\ York YO1 5DD, England. \\ $\S$ Herb Creek, Old Waratah Road, Fish Creek, \\ Victoria 3959, Australia.
}

The response of pollinators to the pseudo-cryptic polymorphism of dark/light keel colour in Lotus corniculatus has been studied experimentally. Some evidence was obtained that the bumble-bees Bombus lapidarius and B. terrestris forage more dark-keeled flowers in dull and overcast conditions than in bright sunlight.

The distribution of herbivorous insects within the flowers of $L$. corniculatus suggests that they do not distinguish between the keel colour phenotypes.

The entire seed production of pre-marked plants growing at two sites was recovered. Analysis of the data obtained from one site showed that the phenotypes did not differ significantly in any of the following characteristics: pods produced, seeds produced, seeds per pod, seed herbivores, seed herbivores per pod, damaged seeds, and germination patterns. At the second site no germination trials were effected, but even more closely similar values for seed production and overall seed herbivory of the two keel colour phenotypes were obtained.

At the latter site the herbivorous wasp Eurytoma platyptera was commoner in the pods of light-keeled plants and light-keeled plants produced more seeds than the dark-keeled plants later in the season even though light-keeled plants tend to flower earlier.

\section{INTRODUCTION}

Most European populations of the legume Lotus corniculatus L. are polymorphic for the character of keel petal colour, with some individuals producing flowers that have entirely yellow ("light") keel petals and the remainder having red-brown ("dark") keel tips. The inheritance of this character is tetrasomic, with dark keels dominant (Hart and Wilsie, 1959). This has been confirmed in British material (Ramnani and Jones, 1984b). Many $L$. corniculatus populations are also polymorphic for the presence or absence of cyanogenesis by the leaves and/or petals, but there is no evidence of a relationship between the expression of the cyanogenic and keel colour phenotypes in natural populations (Jones and Crawford, 1977; Compton et al., 1983a,b).

Dark-keeled plants are more numerous in the north-east than elsewhere in Britain (Jones and
Crawford, 1977; Abbott, 1981; Crawford and Jones, 1986). A steep cline in keel colour frequencies has also been recorded in the Jostedal Valley (Norway), where dark-keeled plants are found to be less numerous in the peri-glacial northern populations (Compton et al., 1983a). Despite being genetically dominant, the dark-keel phenotype only occasionally forms a large majority in natural populations, and in the coastal regions of mainland Europe it is light-keeled individuals which are most frequently encountered (Jones and Crawford, 1977). Inland the dark-keel phenotype is commoner and a clear association between the frequency of the dark-keeled form and altitude has been described for the Auvergne, the Pyrenees and the Haute-Savoie in France and also in Austria (Baker and Jones, 1986). This implies that in many areas dark-keeled plants are at some disadvantage relative to their light-keeled neighbours. 
The relative fitness of the phenotypes has been examined by Jones and Crawford (1977), who failed to detect any differences in winter survival or in seed production under experimental conditions. These studies did suggest that dark-keeled plants may begin flowering later than the lightkeeled plants and this is examined further in this report. The main purpose, however, is to describe the behaviour of pollinator bees in experimental plots containing mixtures of the two keel colours, and to compare seed production and herbivore loads of plants growing in natural conditions.

\section{METHODS AND RESULTS}

\section{Localities}

Natural populations of $L$. corniculatus were sampled at the following U.K. locations: Eppleworth Quarry, E. Yorks (TA 023327); Wharram Quarry, N. Yorks (SE 859653); Cottingham/Walkington, E. Yorks (TA 020257) and Cauldon Lowe, Staffs (SK 083486). Pollination studies were carried out using experimental populations established at the Hull University Botanic Gardens, Cottingham.

\section{Sequential sampling of keel colour frequencies}

L. corniculatus populations were monitored at intervals during the flowering season in order to determine whether the peak flowering periods of the two keel colour phenotypes are different. Sections of the populations at Eppleworth and Wharram were sampled systematically by removing a single flower umbel from plants growing at least one metre apart. $L$. corniculatus clones readily and this sampling method aims to reduce the probability of repeat sampling of the same individual (Jones, 1977).

The variation recorded for keel colour frequencies is given in table 1 . In each sequence the first sample collected contained a lower proportion of the dark-keeled morph than in subsequent samples although correlation analysis on the 1978 and 1981 sets of data failed to show an association between the proportion of dark-keeled plants flowering and the sampling date. These data indicate that sequential sampling should begin much earlier in the flowering season. Data collected recently at other sites at approximately the same latitude show clearly the earlier flowering of the light-keeled plants (Crawford and Jones, in preparation).
Table 1 Number of plants with dark and light keel petals observed during sequential sampling of $L$. corniculatus populations. Plants were sampled at $1 \mathrm{~m}$ plus intervals

(a) Eppleworth Quarry, 1978

\begin{tabular}{rlll}
\hline & \multicolumn{2}{l}{ Keel colour } & \\
\cline { 2 - 3 } Date & Light & Dark & $\%$ Dark \\
\hline 20.7 .78 & 30 & 15 & $33 \cdot 3$ \\
27.7 .78 & 12 & 14 & $53 \cdot 8$ \\
15.8 .78 & 18 & 19 & $51 \cdot 4$ \\
30.8 .78 & 15 & 16 & $51 \cdot 6$ \\
4.9 .78 & 9 & 9 & $50 \cdot 0$ \\
19.9 .78 & 6 & 11 & $64 \cdot 7$ \\
\hline
\end{tabular}

$r_{[4]}$ arc sine transformed per cent dark keels with date $=0.740$, $P>0.05$.

(b) Wharram Quarry, 1974 and 1981

\begin{tabular}{rcrl}
\hline & \multicolumn{2}{l}{ Keel colour } & \\
\cline { 2 - 3 } \multicolumn{1}{l}{ Date } & Light & Dark & $\%$ Dark \\
\hline 12.6 .74 & 65 & 35 & $35 \cdot 0$ \\
6.8 .74 & 106 & 94 & $47 \cdot 0$ \\
13.8 .74 & 136 & 100 & $44 \cdot 7$ \\
9.6 .81 & 89 & 57 & $39 \cdot 0$ \\
25.7 .81 & 70 & 66 & $48 \cdot 5$ \\
11.8 .81 & 103 & 107 & $51 \cdot 0$ \\
18.8 .81 & 144 & 136 & $48 \cdot 6$ \\
28.8 .81 & 99 & 70 & $41 \cdot 4$ \\
\hline
\end{tabular}

$I_{[3]}$ arc sine transformed per cent dark keels with date (1981 data $)=0.501, P>0.05$.

\section{Pollinator responses to keel colour polymorphism}

Cultivars of $L$. corniculatus display varying degrees of self-incompatibility and insects are required for successful pollination to take place (Tome and Johnson, 1945; Giles, 1949; Seaney, 1964). Furthermore, Morse (1958) observed that between 12 and 25 visits per flower are required for maximum seed set. With British material collected in the wild all seven plants we have tested so far are self-sterile (Ramnani and Jones, 1984a, $b$ ). The UV reflectance spectrum is such that bees certainly should be able to distinguish between the two types of keel. With dark keels we have found that the reflectance is uniformly low between 222 and $695 \mathrm{~nm}$, a sharp increase occurring at the longer wavelength. Thus to a bee dark keels should appear uniformly black (or grey). Light keels, and also wing and standard petals, show a marked increase in reflectance at $490 \mathrm{~nm}$, reaching a maximum at 625 . There is a subsequent minimum at $695 \mathrm{~nm}$, although this is not as low as with dark keels. The pattern for 
longer wavelengths is essentially the same as for dark keels. Light keels should, therefore, be "beeyellow" (Daumer, 1956). The difference between the dark and light keels appears to be based on different concentrations of anthocyanin rather than on any qualitative differences (J. B. Harborne, personal communication, and $\mathrm{P}$. Kakes, personal communication), but more work needs to be done on the chemistry of the pigments involved.

There appears to be no definitive list of natura! pollinators of L. corniculatus in the U.K., but there is positive evidence that honeybees (McLellan, 1976), Bombus monticola Smith, syn. B. lapponicus (F.) (Yalden, 1982) and B. lucorum (L.) (Yalden, 1983) collect pollen from the plant. Whether small insects are effective pollinators remains to be determined, but Compton (1983) has found that the flowers often contain Meligethes erythropus (Marsham) and Odontothrips loti (Haliday), for example, and as these insects move from flower to flower seeking pollen we are not prepared to exclude them from a list of possible pollinators.

Two experimental plots were established $3 \mathrm{~m}$ apart, each containing mature plants grown from the progeny of a single cross (self-sterile clones A13 and C27). One plot consisted of 71 plants (35 light keel, 36 dark) arranged at random in a $12 \times 6$ matrix, $0.5 \mathrm{~m}$ between plants. The other plot had the same orientation and consisted of 54 plants (27 light keel, 27 dark) arranged systematicaliy in a $9 \times 6$ matrix. Each plant (except those at the edges) was surrounded by four light and four dark keeled plants, with two plants of each phenotype forming the "diagonal" neighbours. Monitoring of bees entering the plots was carried out during July 1980. Bees were not recognisable individually and some may have had several of their visits to the plots recorded. The plants were in flower throughout the observation period, but it was not possible to count the number of flowers available to the pollinators at any given time.

The flight of individual bees was recorded on an audio-taperecorder and the information was later transcribed to data sheets. By this means it was possible to follow the travels of individual bees without difficulty. For example, one bee foraged the plants in the random plot for 37 minutes, visited 50 of the 71 plants ( 27 dark, 23 light) and foraged in 262 dark and 117 light flowers. The position of a plant was identified by its grid reference and the number of flowers visited on that plant was recorded. The data for the two plots were collected separately. On many days two people watched the plots, one scoring activity in the systematic plot and the other recording from the random plot. Scorers were assigned to the plots at random. Two types of visiting were recorded. Sometimes a bee would inspect a flower but not enter it. This has been scored as inspecting. A visit, involving pollen and/or nectar gathering was recorded as foraging.

When a bee left a plant and visited a flower on a different plant the movement was counted as a single pollinator flight (e.g., as in table 2).

Two species of bees regularly foraged both areas (Bombus lapidarius L. and Bombus terrestris L.), while a third species, the solitary Andrena sp., was only numerous on the random plot. Comparisons of the numbers of flights made between plants indicate that none of the species showed a preference for flying to plants of the same phenotype as the one from which they had left, nor to plants of the alternative phenotype (tables 2 and 3 ).

In the random plot the bee species were not homogeneous in their foraging behaviour (table 4). As there were 35 light and 36 dark-keeled plants in the plot we have a basis for testing the preference of the bees. Clearly Bombus terrestris and the Andrena sp. show no preference, whereas $B$. lapidarius does show a preference for dark-keeled plants $\left(\chi_{[1]}^{2}=9 \cdot 61,0 \cdot 01>P>0 \cdot 001\right)$. A similar test of significance cannot be used on the number of individual flowers foraged because the total number of flowers of each phenotype was not known, but the pattern is the same as for the foraging of plants.

This pattern was not repeated in the systematic plot, where both Bombus species foraged similar numbers of light and dark-keeled flowers (table 4b).

The prevailing weather conditions were noted at the beginning of each recording sequence so allowing the flights to be grouped as occurring in either "sunny" or "overcast" conditions. Flights during periods of intermediate or variable weather conditions have been excluded from the analysis. During overcast conditions $B$. lapidarius made a higher proportion of foraging flights to dark-keeled plants than it did in sunny conditions (random plot only), $\chi_{[1]}^{2}=10.55, P<0.001$ (based on 35 light and 36 dark-keeled plants), and foraged more dark-keeled flowers (table 5a). Neither of the other species gave any indication that their flight activity in the random plot was being influenced by the weather.

The behaviour of the two Bombus species in the systematic plot shows that while they were not foraging on more dark-keeled plants during overcast conditions they were foraging more flowers 
Table 2(a) The frequency of pollinator flights between plants of $L$. corniculatus for 35 bees

Bombus lapidarius

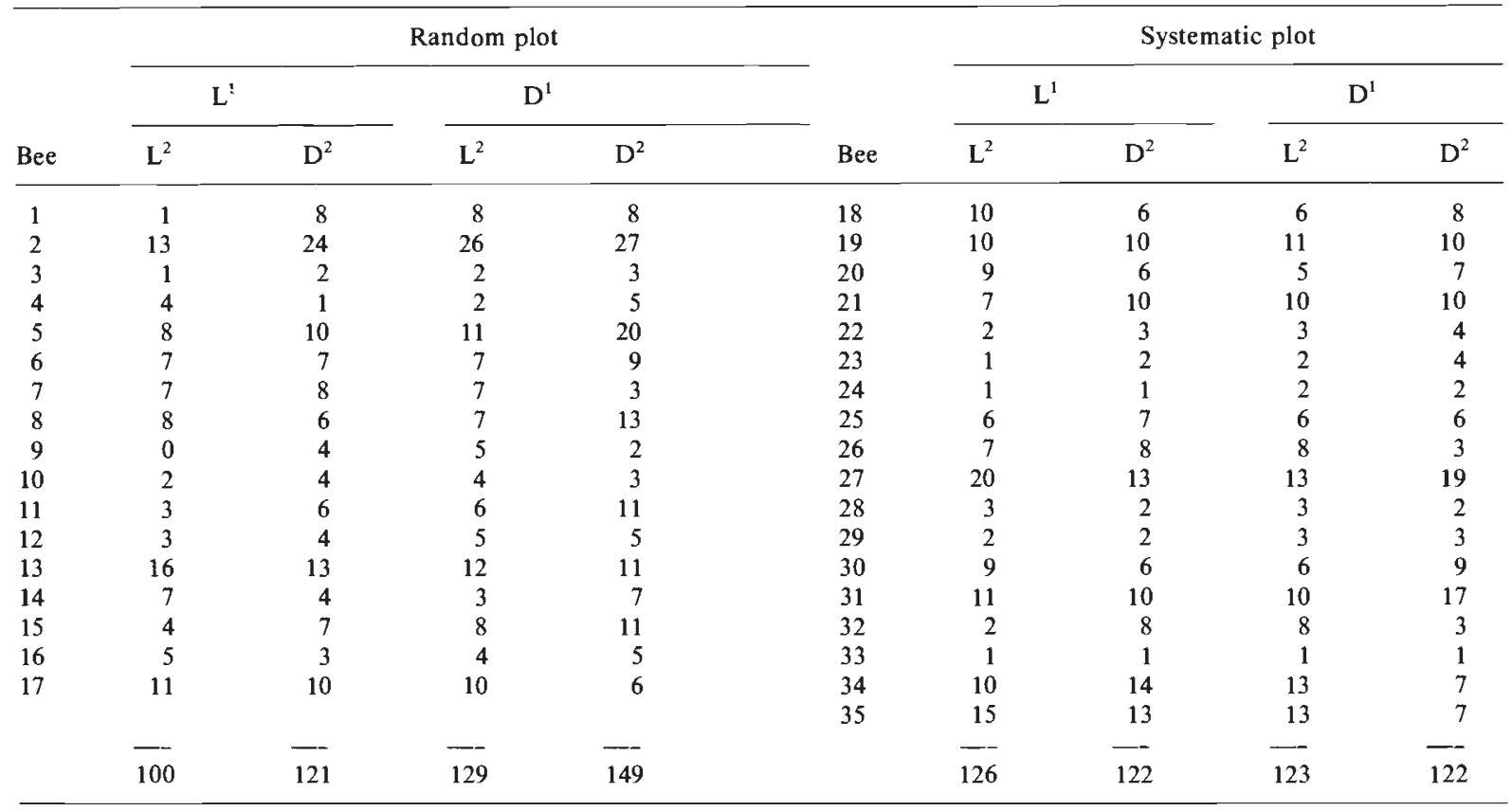

Random plot: $\chi_{[1]}^{2}$ for total values $=0.07, P>0.05$; Heterogeneity $\chi_{\lceil 16]}^{2}=21 \cdot 55, P>0.05$. Systematic plot: $\chi_{\lceil 11}^{2}=0 \cdot 18, P>0.05$; Heterogeneity $\chi_{[17]}^{2}=17.63, P>0.05 . \mathrm{L}^{1}=$ Light keeled plant from which flight began. $\mathrm{D}^{1}=$ Dark keeled plant from which flight began. $\mathrm{L}^{2}=$ Light keeled plant on which flight ended. $\mathrm{D}^{2}=$ Dark keeled plant on which flight ended.

on each dark-keeled plant under these conditions (table 5b).

\section{Flower production}

The numbers of flowers present on the umbels of light and dark-keeled plants growing at Eppleworth Quarry were compared. Collecting by eye at $1 \mathrm{~m}$ plus intervals is not an appropriate sampling method in this case because umbels with large numbers of flowers are liable to be chosen preferentially. As an alternative, small quadrats were placed at random over $L$. corniculatus plants and all the flower umbels inside were removed and scored. The results (table 6) suggest that the light and dark-keeled plants produce umbels which bear similar numbers of flowers.

\section{Colonisation of flowers by phytophagous insects}

L. corniculatus flowers support a well developed community of phytophagous insects, some of which can cause considerable damage to the petals and immature seeds (Compton, 1983). The distri- bution of these insects was investigated to determine whether they showed a preference for one or other of the keel colour phenotypes. Flower umbels were sampled systematically at intervals of at least one metre, then stored individually prior to freezing and subsequent dissection.

Three species of beetles (Coleoptera) regularly feed in the flowers of $L$. corniculatus in northern England. Apion loti Kirby larvae develop inside the seed pods of the plants, where they feed on the ovules and immature seeds. Hypera plantaginis (DeGeer) larvae feed on the outside of the pod, devouring seeds, pods and petals. The third species, Meligethes erythropus (Marsham) appears to be less destructive as both the larvae and adults are pollen feeders. Several species of thrips (Thysanoptera) also occur in the flowers, of which the commonest are Odontothrips loti (Haliday) and Aeolothrips tenaicarnis Bagnall. Both species feed on the surface tissues of the immature seed pod, but the latter may also be a facultative predator of small arthropods and other thrips (Ward, 1973). The aphid Acyrthosiphon loti (Theobald) is less frequently encountered. Its feeding habits were not observed. 
Table 2(b) Comparisons of the frequency of pollinator flights between plants of L. corniculatus for 24 Bombus terrestris and 14 Andrena sp.

Bombus terrestris

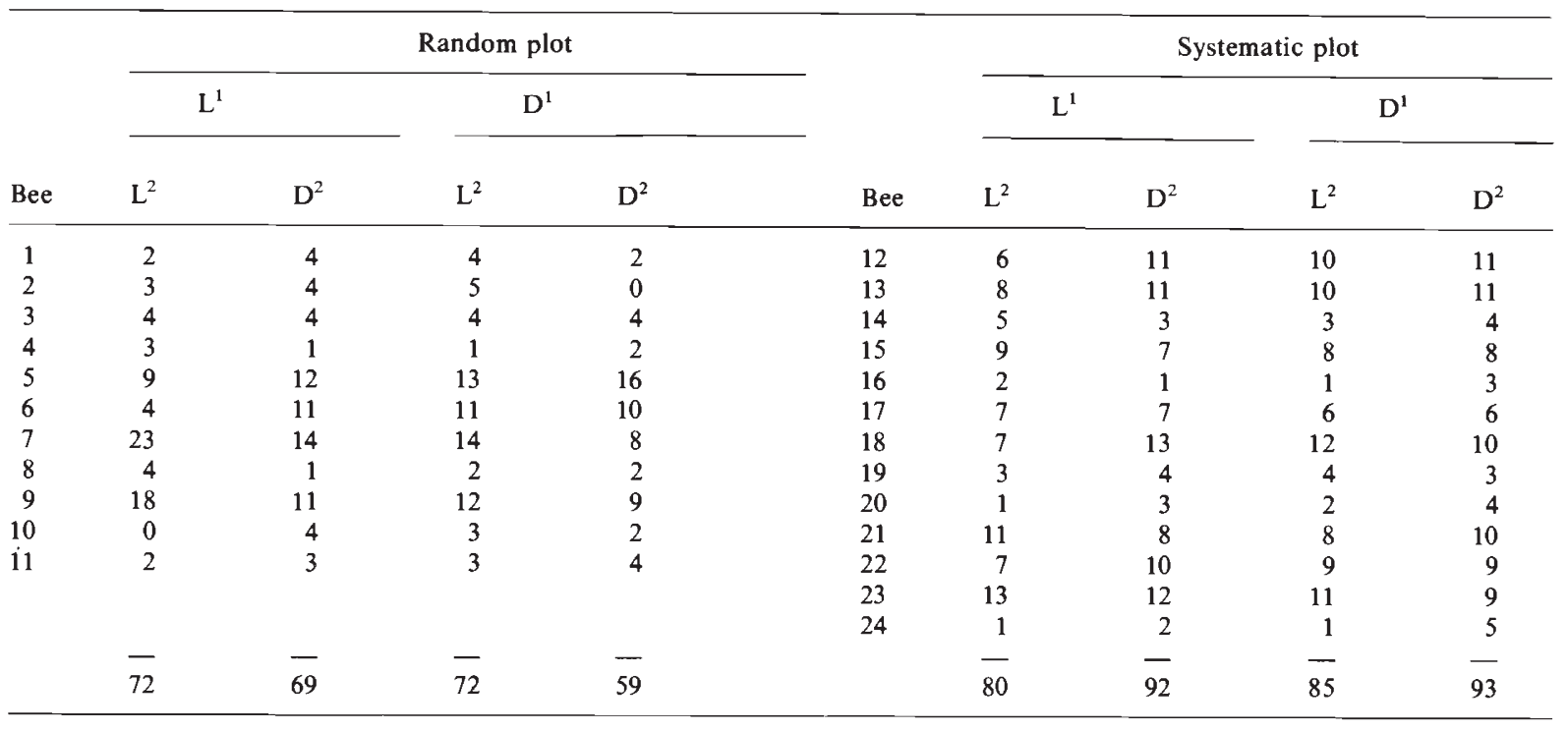

$\chi_{[1]}^{2}$ for total values $=0.41, P>0.05 ;$ Heterogeneity $\chi_{[10]}^{2}=13.46, P>0.05 . \chi_{[1]}^{2}=0.05 ; P>0 \cdot 05$. Heterogeneity $\chi_{[12]}^{2}=5 \cdot 85, P>0.05$.

Andrena sp.

\begin{tabular}{|c|c|c|c|c|}
\hline \multirow[b]{3}{*}{ Bee } & \multicolumn{4}{|c|}{ Random plot } \\
\hline & \multicolumn{2}{|c|}{$\mathrm{L}^{1}$} & \multicolumn{2}{|c|}{$\mathrm{D}^{1}$} \\
\hline & $\mathrm{L}^{2}$ & $\mathrm{D}^{2}$ & $\mathrm{~L}^{2}$ & $\mathrm{D}^{2}$ \\
\hline 1 & 2 & 1 & 0 & 0 \\
\hline 2 & 2 & 1 & 2 & 4 \\
\hline 3 & 5 & 5 & 4 & 11 \\
\hline 4 & 2 & 2 & 2 & 3 \\
\hline 5 & 6 & 9 & 9 & 4 \\
\hline 6 & 10 & 3 & 4 & 2 \\
\hline 7 & 5 & 2 & 2 & 0 \\
\hline 8 & 7 & 4 & 5 & 8 \\
\hline 9 & 12 & 13 & 13 & 14 \\
\hline 10 & 3 & 5 & 4 & 7 \\
\hline 11 & 16 & 13 & 13 & 10 \\
\hline 12 & 4 & 5 & 5 & 11 \\
\hline 13 & 8 & 10 & 11 & 6 \\
\hline \multirow[t]{3}{*}{14} & 4 & 3 & 3 & 4 \\
\hline & - & - & - & - \\
\hline & 86 & 76 & 77 & 84 \\
\hline
\end{tabular}

The distributions of the insects within the flowers of $L$. corniculatus suggest that they do not distinguish between the keel colour phenotypes (table 7). On one occasion an excessive number of adult thrips was found in dark-keeled flowers, but this result was not repeated in the other samples and was clearly atypical.

\section{Seed production and herbivory}

The most accurate measure of the success of a plant in evolutionary terms is the number of successfully reproducing offspring which it produces during its lifetime. This value is generally unobtainable particularly for a long-lived cloning 
Table 3 The frequency of pollinator flights between plants of L. corniculatus. Between species comparisons

(a) Random plot

\begin{tabular}{lrrrr} 
& \multicolumn{2}{c}{$\mathrm{L}^{1}$} & \multicolumn{2}{c}{$\mathrm{D}^{1}$} \\
\cline { 2 - 5 } & \multicolumn{1}{c}{$\mathrm{L}^{2}$} & \multicolumn{1}{c}{$\mathrm{D}^{2}$} & \multicolumn{1}{c}{$\mathrm{L}^{2}$} & \multicolumn{1}{c}{$\mathrm{D}^{2}$} \\
\hline Bombus lapidarius & 100 & 121 & 129 & 149 \\
Bombus terrestris & 72 & 69 & 72 & 59 \\
Andrena & 86 & 76 & 77 & 84 \\
\hline
\end{tabular}

$\chi_{[7]}^{2}=10 \cdot 11, P>0.05\left(\right.$ a $2 \times 2 \times 3$ contingency $\left.\chi^{2}\right)$

(b) Systematic plot

\begin{tabular}{lrrrr} 
& \multicolumn{2}{c}{$\mathrm{L}^{1}$} & \multicolumn{2}{c}{$\mathrm{D}^{1}$} \\
\cline { 2 - 5 } & \multicolumn{1}{c}{$\mathrm{L}^{2}$} & \multicolumn{1}{c}{$\mathrm{D}^{2}$} & \multicolumn{1}{c}{$\mathrm{L}^{2}$} & \multicolumn{1}{c}{$\mathrm{D}^{2}$} \\
\hline Bombus lapidarius & 126 & 122 & 123 & 122 \\
Bombus terrestris & 80 & 92 & 85 & 93
\end{tabular}

$\chi_{[4]}^{2}=1 \cdot 11, P>0 \cdot 05\left(\right.$ a $2 \times 2 \times 2$ contingency $\left.\chi^{2}\right)$

perennial and in most cases viable seed production provides the best available estimate of relative fitness. Comparisons of the seed production of light and dark-keeled $L$. corniculatus were obtained by harvesting the entire seed production of premarked plants growing at Cauldon Lowe and at Wharram Quarry. Animals feeding in the pods were also identified and counted, together with any of their parasites that were present. Phytophagous species recorded inside the pods were Apion loti, Eurytoma platyptera (Walker), (Hymenoptera) and Cydia compositella (F), (Lepidoptera). The biology of these species, and their associated parasite complex, has been described elsewhere (Compton, 1983). Any insects which had completed their development and vacated the pods would not have been detected easily by this sampling regime. Normally it is only adult $A$. loti and prepupal larvae of $C$. compositella that can escape from undehisced pods. The head capsules of $\boldsymbol{A}$. loti larvae were recovered wherever possible and counted.

In June 1973 the seeds of the 1972 collection from Cauldon Lowe were examined, counted (using the Decca Mastercount) and placed on damp filter paper in petri dishes. In this way it was possible to distinguish three groups of seeds: a few seeds germinated immediately (year 1 germination); a large number of hard seeds did not imbibe water; the remainder swelled, but did not germinate. This last group included seeds damaged by insects, immature seeds and seeds inviable for other reasons. It was not possible to examine all 31,704 seeds individually for evidence of damage
Table 4 The foraging patterns of pollinators given a choice between dark and light-keeled $L$. corniculatus. These data differ from those in table 2 in two ways: (1) the first plant foraged is included and (2) plants inspected, but not foraged are excluded

(a) Random plot

\begin{tabular}{llll} 
& \multirow{2}{*}{$\begin{array}{l}\text { No. of } \\
\text { observations }\end{array}$} & \multicolumn{2}{c}{ No. of plants foraged } \\
\cline { 3 - 4 } \cline { 3 - 4 } & Dark Keel & Light Keel \\
\hline Bombus lapidarius & 17 & 230 & 163 \\
Bombus terrestris & 11 & 108 & 118 \\
Andrena & 14 & 135 & 134 \\
\hline
\end{tabular}

$\chi_{[2]}^{2}=8 \cdot 11, P<0.05$

\begin{tabular}{llll}
\hline & & \multicolumn{2}{c}{ No. of flowers foraged } \\
\cline { 3 - 4 } Species & $\begin{array}{l}\text { No. of } \\
\text { observations }\end{array}$ & Dark Keel & Light Keel \\
\hline Bombus lapidarius & 17 & 943 & 603 \\
Bombus terrestris & 11 & 368 & 349 \\
Andrena & 14 & 405 & 470 \\
\hline
\end{tabular}

$\chi_{[2]}^{2}=53 \cdot 03, P<0.001$

(b) Systematic plot

No. of plants foraged

\begin{tabular}{|c|c|c|c|}
\hline \multirow[b]{2}{*}{ Species } & \multirow{2}{*}{$\begin{array}{l}\text { No. of } \\
\text { observations }\end{array}$} & \\
\hline & & Dark Keel & Light Keel \\
\hline Bombus lapidarius & 18 & 198 & 188 \\
\hline Bombus terrestris & 13 & 156 & 146 \\
\hline
\end{tabular}

$\chi_{[1]}^{2}=0.01, P>0.05$

\begin{tabular}{llll}
\hline \multirow{2}{*}{ Species } & \multirow{2}{*}{$\begin{array}{l}\text { No. of } \\
\text { observations }\end{array}$} & \multicolumn{2}{l}{ No. of flowers foraged } \\
\cline { 3 - 4 } & & Dark Keel & Light Keel \\
\hline Bombus lapidarius & 18 & 824 & 704 \\
Bombus terrestris & 13 & 552 & 465 \\
\hline
\end{tabular}

$\chi_{[1]}^{2}=0.04, P>0.05$

by herbivores. From our knowledge of the feeding behaviour of the seed herbivores and their parasites found in these pods (e.g., Compton, 1983) we were able to estimate the minimum number of seeds likely to have been damaged by the insects.

The hard seeds were rescued, washed and dried and in 1974 they were scarified and the germination test was repeated. The overall germination rate (year 2 germination) among these seeds was $84 \cdot 10$ per cent which compares favourably with formal genetical experiments requiring a high germination rate (e.g., Ramnani and Jones, 1984a).

The data obtained are presented in table 8 . Analysis of variance after relevant transformations showed that the phenotypes did not differ significantly in any of the following characters: pods produced, seeds produced, seeds per pod, seed 
Table 5 Foraging of $L$. corniculatus flowers in relation to keel colour and weather conditions

(a) Random plot

No. of plants foraged

\begin{tabular}{|c|c|c|c|c|c|c|c|c|}
\hline \multirow[b]{3}{*}{ Species } & \multirow{2}{*}{\multicolumn{2}{|c|}{ No. of flights }} & \multirow{2}{*}{\multicolumn{2}{|c|}{ Overcast }} & & & & \multirow[b]{3}{*}{$P$} \\
\hline & & & & & \multicolumn{2}{|c|}{ Sunny } & \multirow[b]{2}{*}{$\chi_{[1]}^{2}$} & \\
\hline & Overcast & Sunny & Dark & Light & Dark & Light & & \\
\hline Bombus terrestris & 4 & 7 & 17 & 22 & 91 & 96 & 0.33 & $>0.05$ \\
\hline Andrena & 3 & 11 & 16 & 14 & 123 & 120 & 0.08 & $>0.05$ \\
\hline
\end{tabular}

No. of flowers foraged

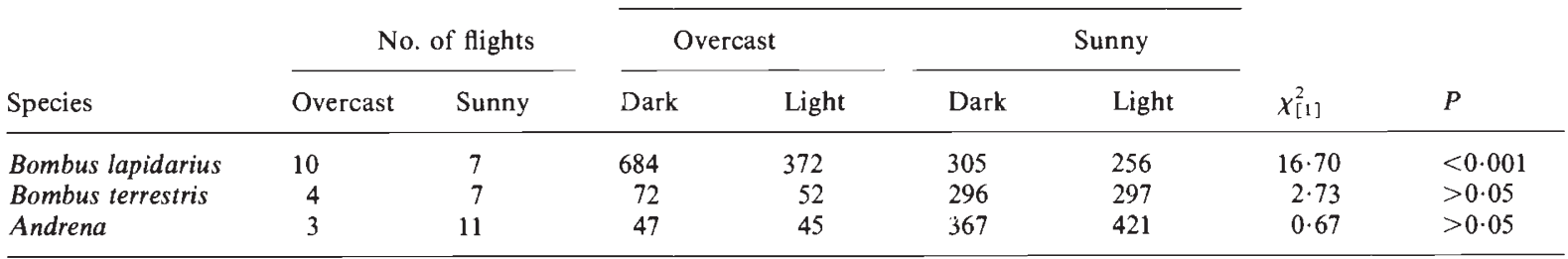

(b) Systematic plot

No. of plants foraged

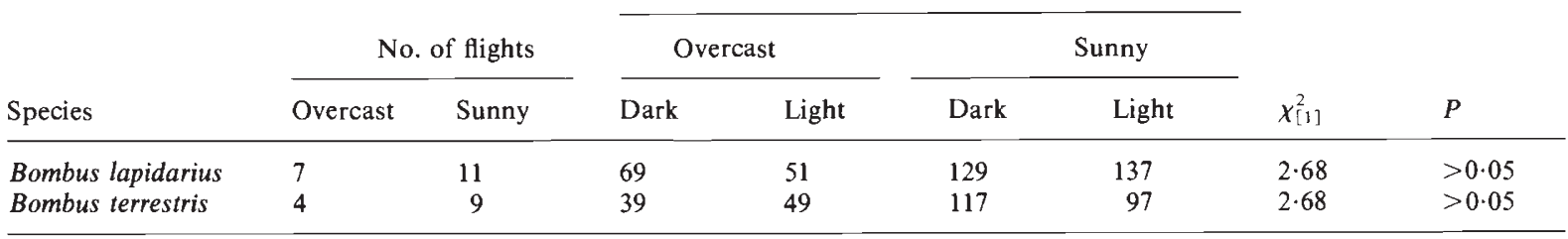

No. of flowers foraged

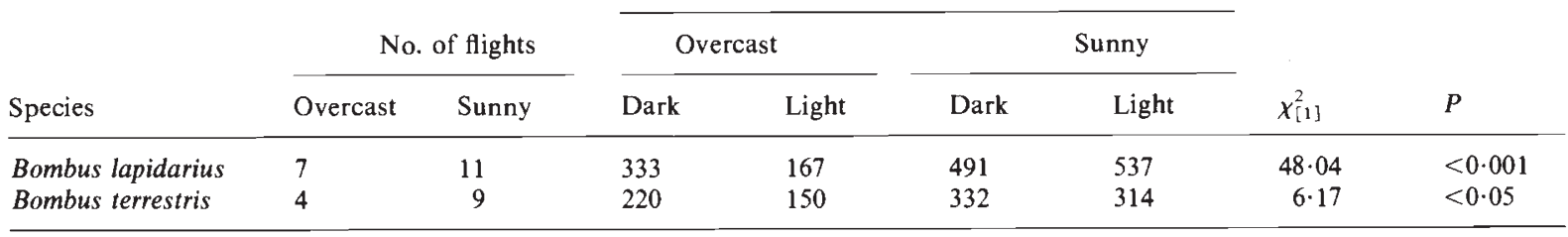

herbivores, seed herbivores per pod, damaged seeds and germination patterns. A similar survey carried out at Wharram Quarry in 1982, which did not include germination studies, obtained even more closely similar values for the seed production and seed herbivory of the two keel colour phenotypes (table 9). For this survey, when a parasite was found it was scored as its host (Compton, 1983).

Note, however, the higher incidence of $E$. platyptera in the pods of light-keeled plants and the larger number of seeds produced by the light keeled plants in the second collection at Wharram Quarry, even though the light-keeled plants tend to flower earlier. The two collections are significantly different from each other $\left(\chi_{[1]}^{2}=54 \cdot 42\right.$, $P \ll 0.001)$.

\section{DISCUSSION}

Variation in the colouration of the keel petals of Lotus corniculatus provides an intriguing example of a polymorphic character of indeterminate role maintained by selective processes that have yet to be discovered. The results presented here indicate that keel colour does not influence pollinator foraging behaviour, nor colonisation by flowerfeeding insects, and we have no evidence of the phenotypes differing in terms of (maternal) reproductive output.

The importance of flower colouration as an isolating mechanism has been reviewed by Kevan (1978), Kay (1978) and others. Different colour forms of the same species are known to differ in their attractiveness to pollinators (e.g., 
Table 6 A comparison of the number of flowers per umbel on light and dark-keeled $L$. corniculatus at Eppleworth Quarry. All the flowers within randomly placed quadrats were recorded

\begin{tabular}{|c|c|c|c|c|c|c|c|}
\hline \multirow[b]{2}{*}{ Period } & \multirow{2}{*}{$\begin{array}{l}\text { Keel } \\
\text { colour }\end{array}$} & \multicolumn{4}{|c|}{ Flowers per umbel } & \multirow[b]{2}{*}{$\chi_{[3]}^{2}$} & \multirow[b]{2}{*}{$P$} \\
\hline & & 1 & 2 & 3 & 4 & & \\
\hline \multirow[t]{2}{*}{1977} & Light & 20 & 6 & 8 & 7 & & \\
\hline & Dark & 8 & 6 & 3 & 0 & $5 \cdot 41$ & $>0.05$ \\
\hline \multirow[t]{2}{*}{1978} & Light & 19 & 25 & 16 & 32 & & \\
\hline & Dark & 15 & 13 & 16 & 13 & $4 \cdot 29$ & $>0.05$ \\
\hline \multirow[t]{2}{*}{ Total } & Light & 39 & 31 & 24 & 39 & & \\
\hline & Dark & 23 & 19 & 19 & 13 & $4 \cdot 11$ & $>0.05$ \\
\hline
\end{tabular}

Heterogeneity $\chi_{[3]}^{2}=5 \cdot 59, P>0.05$.

Mean flowers per umbel: light $2 \cdot 59$, dark $2 \cdot 32$.

Table 7 The colonisation of $L$. corniculatus flowers by insects. One umbel per plant removed at metre plus intervals

(a) Roadside verge between Cottingham and Walkington, 5th July 1978

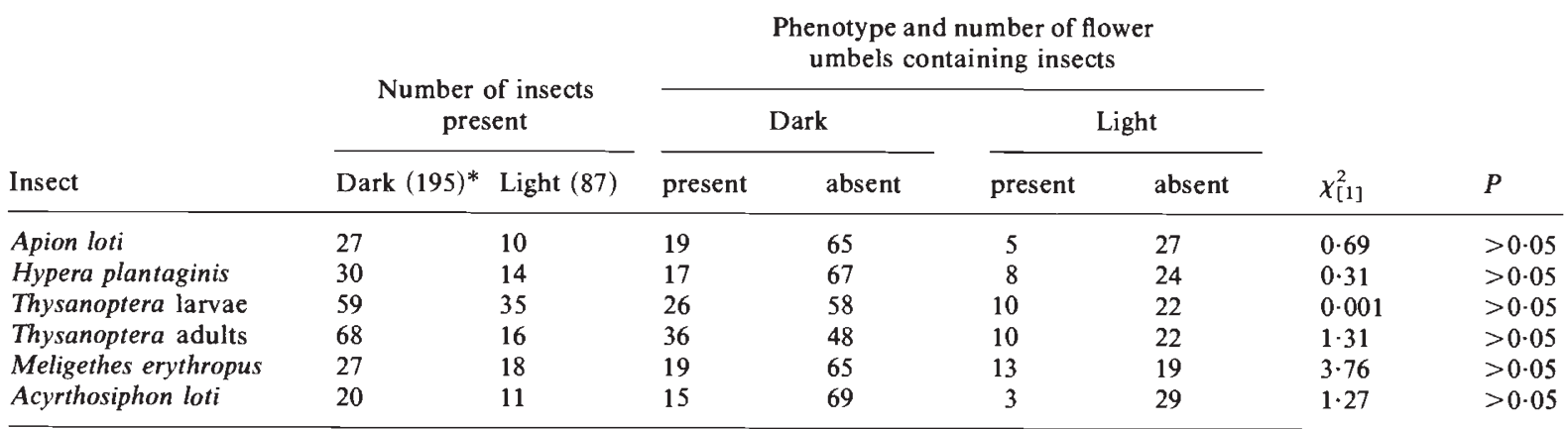

(b) Wharram Quarry, 9th June 1981

\begin{tabular}{|c|c|c|c|c|c|c|c|c|}
\hline \multirow[b]{3}{*}{ Insect } & \multicolumn{6}{|c|}{$\begin{array}{l}\text { Phenotype and number of flower } \\
\text { umbels containing insects }\end{array}$} & \multirow[b]{3}{*}{$\chi_{[1]}^{2}$} & \multirow[b]{3}{*}{$P$} \\
\hline & \multicolumn{2}{|c|}{$\begin{array}{c}\text { Number of insects } \\
\text { present }\end{array}$} & \multicolumn{2}{|c|}{ Dark } & \multicolumn{2}{|c|}{ Light } & & \\
\hline & Dark (206) & Light (312) & present & absent & present & absent & & \\
\hline Apion loti & 213 & 334 & 48 & 6 & 78 & 7 & $0 \cdot 32$ & $>0.05$ \\
\hline Hypera plantaginis & 9 & 21 & 8 & 46 & 16 & 69 & 0.37 & $>0.05$ \\
\hline
\end{tabular}

(c) Wharram Quaryy, 25th July 1986

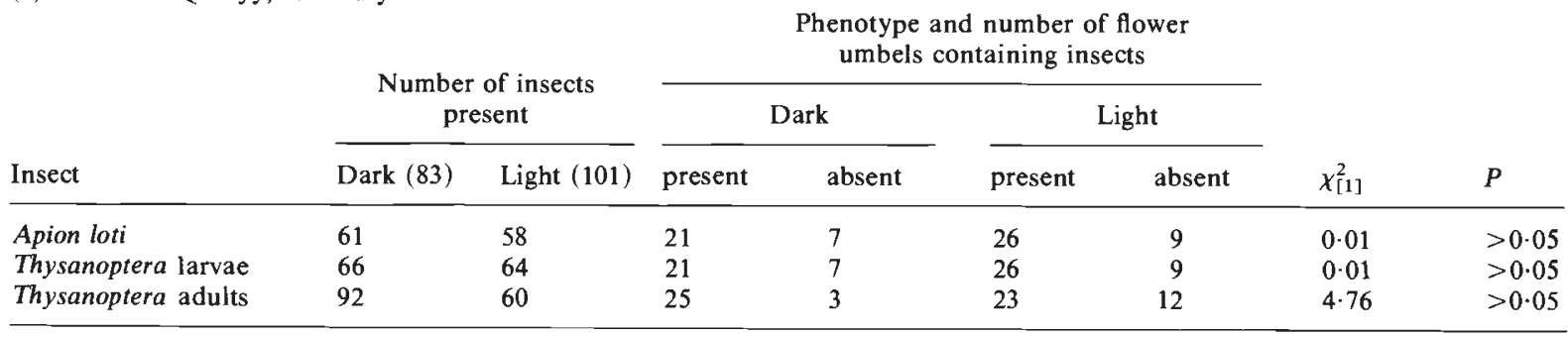

* The number of individual flowers examined. 
Table 8 Seed production by $L$. corniculatus at Cauldon Lowe. The entire seed production of each plant was harvested during September/October 1972. Germination techniques are described in the text

(a) Seed production

\begin{tabular}{|c|c|c|c|c|}
\hline $\begin{array}{l}\text { Keel colour } \\
\text { phenotype }\end{array}$ & Plants & Pods & Seeds & Seeds/pod \\
\hline Dark & 45 & 2813 & 17,213 & $6 \cdot 12$ \\
\hline Light & 48 & 2607 & 14,491 & $5 \cdot 56$ \\
\hline
\end{tabular}

(b) Seed herbivores (including their parasites)

\begin{tabular}{lllll}
$\begin{array}{l}\text { Keel colour } \\
\text { phenotype }\end{array}$ & $\begin{array}{l}\text { Apion } \\
\text { loti }\end{array}$ & $\begin{array}{l}\text { Eurytoma } \\
\text { platyptera }\end{array}$ & $\begin{array}{l}\text { A. loti } \\
\text { /pod }\end{array}$ & $\begin{array}{l}\text { E. platyptera } \\
\text { /pod }\end{array}$ \\
\hline Dark & 589 & 124 & 0.21 & 0.04 \\
Light & 413 & 108 & 0.16 & 0.04 \\
\hline
\end{tabular}

(c) Seed germination

\begin{tabular}{llllll}
$\begin{array}{l}\text { Keel } \\
\text { colour } \\
\text { phenotype }\end{array}$ & $\begin{array}{l}\text { Insect } \\
\text { damaged } \\
\text { seeds }\end{array}$ & $\begin{array}{l}\text { Failed } \\
\text { soft } \\
\text { seeds }\end{array}$ & $\begin{array}{l}\text { Germin- } \\
\text { ated } \\
\text { Year 1* }\end{array}$ & $\begin{array}{l}\text { Germin- } \\
\text { ated } \\
\text { Year 2 }\end{array}$ & $\begin{array}{l}\text { Failed } \\
\text { hard } \\
\text { seeds }\end{array}$ \\
\hline Dark & 1597 & 7599 & 126 & 6711 & 1180 \\
& $9 \cdot 28 \%$ & $44 \cdot 15 \%$ & $0.73 \%$ & $38.99 \%$ & $6.86 \%$ \\
Light & 1141 & 6530 & 143 & 5541 & 1136 \\
& $7 \cdot 87 \%$ & $44 \cdot 06 \%$ & $0.99 \%$ & $38 \cdot 24 \%$ & $7 \cdot 84 \%$
\end{tabular}

* Seeds germinating immediately, without requiring scarification.

Dronamraju, 1960; Lloyd, 1969; Kay, 1976; Levin and Schaal, 1970; Waser and Price, 1981; Brown and Clegg, 1984), while variation in the preferences shown by different pollinators towards Cirsium palustre (L.) colour forms may be responsible for altitudinal differences in morph frequencies (Mogford, $1974 a, b)$. Other studies have yet to consider the role of pollinators in the maintenance of a flower colour polymorphism-e.g. the purpleviolet/white perianth and deep orange/cream white to white stigmata in Crocus scepusiensis (Rehm. et Wol.) Borb. in Poland (Rafinski, 1979). There are also examples where the differential attractiveness of the different colour morphs has been ruled out (e.g., in Platystemon californicus Benth., Hannan, 1981) and others where assertions to this effect have been made (e.g., for Anemone coronaria, Horovitz, 1976).

When a bee forages a Lotus corniculatus flower the wing petals are depressed and the keel is revealed. After the visit the wing petals slowly return to their original position, the whole process taking approximately 15 minutes. If the visible keel petals were a signal to a bee that a flower had recently been visited-and presumably been denuded of nectar-no bee would visit a flower with an obvious keel. Frequently during our observations we noticed bees visiting flowers recently visited by other bees and on at least five separate occasions a bee was seen to return to a flower that it had itself foraged only a few minutes previously.

The data and analyses in tables 2 and 3 show that the pollinator flights between plants are essentially at random with respect to keel colour. The observation that $B$. lapidarius shows a preference for dark-keeled plants in overcast conditions only in the random plot does not make much sense. Obviously assortative mating would result, but the relevance of this behaviour to natural populations-where the distribution of the phenotypes will be neither random nor systematic - cannot be determined. If there were evidence that the darkkeeled plants produced more seeds than lightkeeled plants then we could begin to formulate some testable hypotheses, but the evidence in tables 8 and 9 is equivocal. Overall the two pod collections made at Wharram Quarry show no difference in healthy seed production between the two morphs $(10,425$ from 49 dark and 10,696 from 50 light-keeled plants). At Cauldon Lowe the numbers of viable seeds are 6837 for the dark and 5684 for light-keeled plants. Based on an expected ratio of $45: 48, \quad \chi_{[1]}^{2}=193.79, \quad P \ll 0.001$ showing a marked excess of viable seed from the dark-keeled plants. The analysis of variance based on the seed production of individual plants, however, shows no significant difference between the phenotypes! $\left(V R_{[1,91]}<1\right.$.) The reason for this apparent discrepancy is the very large variation in seed production between individual plants of the same phenotype. Effectively what is happening is that a few individuals are producing a very large number of seeds, so biasing the total seed production of one morph. Unfortunately we have no means of testing whether this is an atypical result nor yet whether it is biologically meaningful in our attempts to explain the genetic polymorphism. Thus there is too much "noise" in the system and we must conclude either that our experimental and observational work has been done on too small a scale or has been looking at the wrong candidates for selective agents or that the selective forces are so finely balanced that genuine differences are beyond the resolution of statistical tests of significance.

There are, however, several features of the keel colour polymorphism in Lotus corniculatus that may well be unique. Firstly, the keel petals are not visible until a flower has been foraged by a bee. 
Table 9 Seed production by $L$. corniculatus at Wharram Quarry. The entire pod production of each plant was harvested on two occasions

Collection 1 (26.8.82)

(a) Seed production

\begin{tabular}{llllll}
$\begin{array}{l}\text { Keel colour } \\
\text { phenotype }\end{array}$ & Plants & Pods & Seeds & Seeds/pod & Chewed seeds \\
\hline Dark & 49 & 361 & 2614 & $7 \cdot 24$ & $386(14 \cdot 8 \%)$ \\
Light & 50 & 302 & 2091 & $6 \cdot 92$ & $2228(85 \cdot 2 \%)$ \\
\hline
\end{tabular}

(b) Seed herbivores (including their parasites*)

\begin{tabular}{llccccc}
$\begin{array}{l}\text { Keel colour } \\
\text { phenotype }\end{array}$ & Apion loti & $\begin{array}{l}\text { Eurytoma } \\
\text { platyptera }\end{array}$ & $\begin{array}{l}\text { Cydia } \\
\text { compositella }\end{array}$ & A. loti/pod & E. platyptera/pod & C. compositella/pod \\
\hline Dark & 166 & 4 & 15 & 0.460 & $0 \cdot 011$ & 0.042 \\
Light & 146 & 56 & 12 & 0.483 & 0.185 & 0.040 \\
\hline
\end{tabular}

Collection 2 (14-15.9.82)

(a) Seed production

Keel colour

\begin{tabular}{lllllll}
$\begin{array}{l}\text { phenotype } \\
\text { Dark }\end{array}$ & Plants & Pods & Seeds & Seeds/pod & Chewed seeds & Healthy seeds \\
\hline Light & 49 & 1523 & 9183 & $6 \cdot 03$ & $986(10 \cdot 7 \%)$ & $8197(89 \cdot 3 \%)$ \\
8 & 50 & 1623 & 9731 & $6 \cdot 00$ & $892(9 \cdot 2 \%)$ & $8839(90 \cdot 8 \%)$ \\
\hline
\end{tabular}

(b) Seed herbivores (including their parasites)

\begin{tabular}{llcllll}
$\begin{array}{l}\text { Keel colour } \\
\text { phenotype }\end{array}$ & Apion loti & $\begin{array}{l}\text { Eurytoma } \\
\text { platyptera }\end{array}$ & $\begin{array}{l}\text { Cydia } \\
\text { compositella }\end{array}$ & A. loti/pod & E. platyptera/pod & C. compositella/pod \\
\hline Dark & 800 & 9 & 31 & 0.525 & 0.006 & 0.020 \\
Light & 739 & 27 & 38 & 0.455 & 0.017 & 0.023 \\
\hline
\end{tabular}

* Each parasite indicates that a herbivore of a particular species would have been there had it not been parasitized (Compton, 1983).

The character is, therefore, partly cryptic. It was for this reason that the behaviour of bees in response to the keel colour variation had to be studied. But, approximately 15 minutes later the keel is no longer visible because the keel petals have returned to their original position. Does it take this length of time for the flower to recharge the nectaries?

Secondly, each flower requires between 12 and 25 active visits by bees for full seed set (Morse, 1958). Thus flowers must remain sufficiently attractive to bees for repeated foraging visits to be made. Thirdly, we now have records from nearly 800 populations of Lotus corniculatus in the U.K. and we have exceedingly few that are monomorphic for keel colour. None of Abbott's (1981) samples from 61 locations in Scotland is monomorphic. In the majority of other examples of flower colour polymorphism most populations are monomorphic and only a few are polymorphic. Such evidence as there is with respect to pollinator behaviour is that they tend to discriminate against a rare morph and this tends to produce monomorphism (e.g., Levin, 1972; Waser and Price, 1981).

We are not prepared to accept that the spectacular west to east cline in the U.K., that is most noticeable between latitudes $53^{\circ} 30^{\prime} \mathrm{N}$ and $54^{\circ} 30^{\prime} \mathrm{N}$ and approximately $210 \mathrm{~km}$ long (Crawford and Jones, 1986), is the result of chance effects. In the west the frequency of dark-keeled plants is almost zero whereas at Flamborough Head the frequency is close to 100 per cent. The pattern of the distribution of the dark-keeled plants in England, Wales and Scotland suggests that strong selection has acted on the polymorphism in the past. Kay (1978) has remarked that older populations of Chrysanthemum coronarum in Greece are essentially monomorphic for petal colour whereas "populations growing in temporarily available roadside and ruderal habitats are heterogeneous with great changes in morph frequency over distances of a few metres". Lotus corniculatus is a common early successional plant particularly on roadside verges, 
in quarries and on waste land where the $\mathrm{pH}$ of the soil is above 5.0. Thus many populations of $L$. corniculatus will be in a state of dynamic flux and polymorphism is only to be expected. On the other hand, well established populations in old pastures and on chalk grassland are always polymorphic.

A few populations in the Netherlands and in France appear to contain only light-keeled individuals (Jones and Crawford, 1977) and no population consisting exclusively of dark keeled plants has been recorded. This is in contrast to the polymorphism of leaf cyanogenesis in $L$. corniculatus where approximately 25 per cent of the recorded populations are monomorphic (Jones, 1977). This may be indicative of frequency dependent selection contributing to the stability of the keel colour polymorphism, with whichever phenotype that is rarer in a population being placed at an increased advantage. But what is the mechanism? It is clearly the case that most of the studies reported here would be unlikely to detect frequency dependent selection because the morphs have occurred at intermediate frequencies. We need to look at natural populations where one or the other morph is rare. A start has been made at Porthdafarch, Anglesey (Compton et al., 1983b), where the dark morph increased in frequency from 5.4 per cent (June 1979) to 20 per cent (May 1982) in one group of plants and from 10.7 per cent (June 1979) to 12.9 per cent (May 1982) in a closely adjacent group of plants. On both occasions the damage to the flowers was recorded, but no evidence of differential herbivory was obtained. Neither the behaviour of pollinators nor seed production was examined.

Many of the ovules produced by $L$. corniculatus fail to develop into mature seed, despite abundant pollination (Stephenson, 1984). Selective abortion of immature seeds is commonly based on the order in which ovules are produced (Stephenson, 1981) and in this situation pollen competition is likely to be intense. Keel colour variation may have a direct influence here with any dark pigment increasing the heat absorbing properties of the petals surrounding the stigma and style and thereby influencing pollen physiology. Unfortunately, some Lotus species are monomorphic for dark keels (e.g., $L$. cytisoides $L$. and $L$. creticus $L$.) and other, sympatric species, are monomorphic for light keels (e.g., L. halophilus Boiss. and Spruner in Boiss. and $L$. ornithopodioides L.). Without detailed comparative information on the pollen physiology and pollination biology of these related species no simple explanation can be based on temperature effects.
In the work reported above we have examined the more obvious fitness characters of seed production, herbivores and the interaction between the flower colour polymorphism and pollinators and not found any differential effects. We have now begun to examine whether there are any pleiotropic effects of keel colour or germination, establishment, resistance to herbivores and survival in a maturing grassland community.

Acknowledgements We are grateful to Dr Richard Keymer, Valerie Fairhurst and Judy Mellors for their help and Mr G. Collier for demonstrating the methods used for obtaining reflectance spectra of keel petals. The financial assistance of the S.E.R.C. and the N.E.R.C. is gratefully acknowledged.

\section{REFERENCES}

АввотT, R. J. 1981. The keel petal colour polymorphism of Lotus corniculatus L. in Scotland. New Phytologist, 88, 549-553.

BAKER, K. AND JONES, D. A. 1986. Altitude and the keel petal polymorphism of Lotus corniculatus L. Journal of Natural History, (in press).

BROWN, B. A. AND CLEGG, M. T. 1984. Influence of flower colour polymorphism on genetic transmission in a natural population of the common morning glory, Ipomoea purpurea. Evolution, 38, 796-803.

COMPTON, S. G. A. 1983. Studies of insects associated with Lotus corniculatus L. Ph.D. Thesis, University of Hull, U.K.

COMPTON, S. G., NEWSOME, D. AND JONES, D. A. $1983 a$. Selection for cyanogenesis in the leaves and petals of Lotus corniculatus L. at high latitudes. Oecologia, 60, 353-358.

COMPTON, S. G., BEESLEY, S. G. AND JONES, D. A. $1983 b$. On the polymorphism of cyanogenesis in Lotus corniculatus L. IX Selective herbivory in natural populations at Porthdafarch, Anglesey. Heredity, 51, 537-548.

CRAWFORD, T. J. AND JONES, D. A. 1986. Variation in the colour of the keel petals in Lotus corniculatus L. 2. Clines in Yorkshire and adjacent counties. Watsonia, 16, 15-19.

DAUMER, K. 1956. Reizmetrische Untersuchungen des Farbensehens der Bienen. Zeitschrift für vergleichende Physiologie, 38, 413-478.

DRONAMRAJU, K. R. 1960. Selective visits of butterflies to flowers: a possible factor in sympatric speciation. Nature, $186,178$.

GILES, W. L. 1949. The morphological aspects of self-fertility in Lotus corniculatus. Ph.D. Thesis, University of Missouri, U.S.A.

HANNAN, G. L. 1981. Flower colour polymorphism and pollination biology of Platystemon californicus Benth. (Papaveraceae). American Journal of Botany, 68, 233-243.

HART, R. H. AND WILSIE, C. P. 1959. Inheritance of a flower colour, brown keel tip, in Lotus corniculatus L. Agronomy Journal, 51, 379-380.

HOROVITZ, A. 1976. Edaphic factors and flower colour distribution in the Anemoneae (Ranunculaceae). Plant Systematics and Evolution, 126, 239-242.

JONES, D. A. 1977. On the polymorphism of cyanogenesis in Lotus corniculatus L. VII. The distribution of the cyanogenic form in western Europe. Heredity, 39, 27-44. 
JONES, D. A. AND CRAWFORD, T. J. 1977. Variation in the colour of the keel petals in Lotus corniculatus L. 1. The polymorphism in western Europe. Heredity, 39, 313-325.

KAY, Q. O. N. 1976. Preferential pollination of yellow flowered morphs of Raphanus raphinastrum by Pieris and Eristalis spp. Nature, 261, 230-232.

KAY, Q. O. N. 1978. The role of preferential and assortative pollination in the maintenance of flower colour polymorphisms. In The Pollination of Flowers by Insects, A. J. Richards (ed.), Academic Press, London, pp 175-190.

KEVAN, P. G. 1978. Floral coloration, its colorimetric analysis and significance in anthecology. In The Pollination of Flowers by Insects, A. J. Richards (ed.), Academic Press, London. pp 51-78.

LEVIN, D. A. 1972. Low frequency disadvantage in the exploitation of pollinators by corolla variants in Phlox. American Naturalist, 106, 453-460.

LEVIN, D. A. AND SCHAAL, B. A. 1970. Corolla colour as an inhibitor of interspecific hybridization in Phlox. American Naturalist, 104, 273-283.

LLOYD, D. G. 1969. Petal colour polymorphism in Leavenworthia (Cruciferae). Contributions from the Gray Herbarium of Harvard University, 198, 9-40.

MCCLELlAN, A. R. 1976. Factors affecting pollen harvesting by the honeybee. Journal of Applied Ecology, 13, 801811.

MOGFORD, D. J. 1974a. Flower colour polymorphism in Cirsium palustre 1. Heredity, 33, 241-256.

MOGFORD, D. J. 1974b. Flower colour polymorphism in Cirsium palustre 2. Pollination. Heredity, 33, 257-263.

MORSE, R. A. 1958. The pollination of bird's-foot trefoil. Proceedings 10th International Congress of Entomology, 4, 951-953.
RAFINSKI, J. N. 1979. Geographic variability of flower colour in. Crocus scepusiensis (Iridaceae). Plant Systematics and Evolution, 131, 107-125.

RAMNANI, A. D. AND JONES, D. A. 1984a. Genetics of cyanogenesis, cyanoglucoside and linamarase production in the leaves of Lotus corniculatus L. Pakistan Journal of Botany, 16, 145-154.

RAMNANI, A. D. AND JONES, D. A. 1984b. Inheritance of the brown keel tip character in Lotus corniculatus L. Bangladesh Journal of Botany, 13, 52-59.

TOME, G. A. AND JOHNSON, I. J. 1945. Self- and cross-fertility relationships in Lotus corniculatus L. and Lotus tenuis Wald. et Kit. Journal of the American Society of Agronomy, 45, 1011-1022.

SEANEY, R. R. 1964. Cross and self seed set in bird's-foot trefoil plants selected for self-fertility. Crop Science, 4, 440-441.

STEPHENSON, A. G. 1981. Flower and fruit abortion: proximate causes and ultimate functions. Annual Review of Ecology and Systematics, 12, 253-279.

STEPHENSON, A. G. 1984. The regulation of maternal investment in an indeterminate flowering plant (Lotus corniculatus). Ecology, 65, 113-121.

WARD, L. K. 1973. Thysanoptera occurring in flowers of a chalk grassland. Entomologist, 106, 97-113.

WASER, N. M. AND PRICE, M. V. 1981. Pollinator choice and stabilizing selection for flower colour in Delphinium nelsonii. Evolution, 35, 376-390.

YALDEN, P. E. 1982. Pollen collected by the bumblebee Bombus monticola Smith in the Peak District, England. Journal of Natural History, 16, 823-832.

YALDEN, P. E. 1983. The pollen collected by Bombus lucorum (L.) (Hym. Apidae) in the Peak District, England. Entomo logists Monthly Magazine, 119, 105-109. 